7?

columns and other psychiatrists on how this can best be achieved. The consultation form, which has been circulated widely, can also be downloaded from the College website http://www.rcpsych.ac.uk/membership/ ConsultAsso_06.pdf

\section{Choosing a career in child and adolescent psychiatry}

Lamb et al (Psychiatric Bulletin, February 2006, 30, 61-64) have reported the views and experiences of trainees in child psychiatry placements and their influence on the choice of child and adolescent psychiatry as a career.

The College recommends that 'trainees should have considerable experience in child and adolescent psychiatry at senior house officer level'. However, it seems that by the time trainees start a child psychiatry placement most have already decided on their career plan.

Senior house officers are accustomed to working within in-patient adult psychiatry units. The transition to a child and adolescent psychiatry placement can be disconcerting. Trainees have to work within a multidisciplinary team where their role and objectives are unfamiliar and seem remote from adult services. Trainees also find that their skills and work experience are not centre stage.

The College specifies that probably the most important ingredient of clinical training is regular direct supervision either individually or in a small group by the consultant (and where available) by specialist registrars. Regular direct supervision would also be valuable to help trainees reflect on their career goals.

We believe that providing a mentor (a senior colleague, specialist registrar) at the beginning of the placement, early involvement in novel training experiences (e.g. family therapy) and in-house workshops and seminars (e.g. child protection issues) could help create a rewarding training experience that could encourage trainees to perceive child psychiatry as a future career

*A. Cadinouche Senior House Officer in Psychiatry, Northgate Clinic, Edgware Community Hospital, Middlesex HA8 OAD,

e-mail: haac@doctor.org.uk,

F. Gainza Consultant in Child and Adolescent Psychiatry, Northgate Clinic, Edgware Community Hospital, Middlesex

\section{Disseminating psychological skills in old age psychiatry services}

It was encouraging to read about the level of interest in psychological therapies for older people in Wales (Psychiatric Bulletin, January 2006, 30, 10-11). Older people will become more aware of psychological therapies and will request them more in the future.
The multidisciplinary team training in cognitive-behavioural therapy (CBT) which was devised and developed by Chris Williams is aimed at training a community mental health team in basic CBT skills, without the jargon associated traditionally with CBT. Hence, it is easily accessible to team members who have no formal training in the discipline. The system is designed to be used in part or whole by practitioners and can therefore provide a range of sessions for varied needs. Training material can be downloaded from http://www.calipso.co.uk

Having trained in Glasgow, I am now imparting these skills to my colleagues from the multidisciplinary team in north Dublin and they have been well received. It is difficult for any service to gain protected time for training. Whitfield et al (Psychiatric Bulletin, February 2006, 30, 58-60) highlight the need for supervision, the development and maintenance of CBT skills as well as for the training and supervision of others. I suggest that the challenge in disseminating these skills is to locate and establish local centres of expertise which would provide supervision and ongoing training. This might prove particularly difficult in areas where no such therapies have previously been available.

Fiona Fenton Consultant in Old Age Psychiatry, Mater Misericordiae Hospital, 61 Eccles St, Dublin 7, e-mail: fmfenton@eircom.net

Evans and Reynolds highlight the limited access to psychological therapies for older people in Wales. Similar problems exist in England despite a commitment to psychological therapies in the National Service Framework for Older People (Department of Health, 2001) and the National Institute for Clinical Excellence guidelines for anxiety and depression (NICE, 2004).

A survey across Suffolk, Norfolk and Cambridgeshire for the National Institute for Mental Health in England (East Region) in 2004 showed that in several areas the availability of psychologists was very limited (survey available from NIMHE East Region or by e-mail from dm214@aol.com). College guidelines suggest there should be 0.5 psychologists per 10000 population aged over 65 years, but few areas achieve this level and some have none. Interviews with community team leaders revealed that several had unfilled psychology posts owing to recruitment difficulties. Psychologists frequently support memory clinics, but the availability of drugs enhancing cognition has also increased the need for psychologists in the community.

Psychology resources are key for the supervision of other staff providing psychological therapies, behavioural therapy and psychometry where a diagnosis of dementia is in doubt.
Unfortunately our survey revealed insufficient $A$ grade psychologists to supervise assistants, and therefore the old age specialty was not attracting new entrants. Community psychiatric nurses (CPNs) are often trained in psychological therapies, but with a threefold variation in CPN numbers (from 2000 to 7000 population aged over 65 years per CPN), time for delivering these therapies was often limited. If we are to provide psychological therapies to older people with mental illness, the shortage of psychology resources needs to be addressed.

DEPARTMENT OF HEALTH (2001) National Service Framework for Older People. London: Department of Health.

NATIONAL INSTITUTE FOR CLINICAL EXCELLENCE (2004) NICE Guidelines to Improve the Treatment and Care of People with Depression and Anxiety. London: NICE.

Susan Bedford Associate Specialist in Old Age Psychiatry, Wonford House Hospital, Dryden Road Exeter EX2 5AF, e-mail: dm214@aol.com

\section{Psychiatric comorbidity in foetal alcohol syndrome}

With increasing media interest and public awareness and reports from North America regarding the prevalence of psychiatric comorbidity in foetal alcohol syndrome (FAS; Famy et al, 1998), concerns are being raised locally as to the knowledge of mental healthcare professionals of this issue. Clinical work with this group suggested that the wider mental health community has limited knowledge of FAS as a condition, despite international figures suggesting a prevalence rate of $1 \%$ in the community (O'Leary, 2004). Hence one of us (R.A.S.M.) devised a brief questionnaire to determine mental health practitioners' knowledge of the condition. The questionnaire was used at three local academic programmes attended by a mix of mental healthcare professionals.

Everyone $(n=33)$ had heard of FAS as a condition but only five professionals felt able to recognise it. One person (a psychologist) considered FAS in the differential diagnosis and nine knew where to refer a person with FAS if the diagnosis was suspected or found. Only one individual with foetal alcohol spectrum disorder (FASD) was known to those professionals attending the programmes.

These results are similar to those from other studies (Nanson et al, 1995) and highlight the need for education in this area in order to guide UK practitioners in the recognition of the condition and what can be done to help affected individuals and their families. We believe there is an 
urgent need for resources to undertake this task.

FAMY, C., STREISSGUTH, A. P. \& UNIS, A. S. (1998) Mental illness in adults with fetal alcohol syndrome or fetal alcohol effects. American Journal of Psychiatry, $155,552-554$

NANSON, J. L., BOLARIA, R., SNYDER, R. E., et al (1995) Physician awareness of fetal alcohol syndrome: survey of pediatricians and general practitioners. Canadian Medical Association Journal, 152 1071-1076

O'LEARY, C. M. (2004) Fetal alcohol syndrome: diagnosis, epidemiology and developmental outcomes. Journal of Paediatrics and Child Health, $\mathbf{4 0}$ $2-7$

*Raja A.S. Mukherjee Honorary Lecturer, Division of Mental Health, Social and Developmenta Psychiatry, St George's, University of London, London SW17 0RE, e-mail: rmukherj@sgul.ac.uk, Sheila Hollins Professor, Division of Mental Health, Social and Developmental Psychiatry St George's, University of London, Jeremy Turk Reader in Developmental Psychiatry, Division of Clinical Development Sciences,

St George's, University of London

\section{Flexible training}

I am a senior house officer who has been training under a flexible training scheme for the past 2 years. Like any other trainee in psychiatry, I have read with great interest the recent publications regarding the imminent changes in training and I have wondered how flexible training will be affected by the introduction of modular and work place-based assessments.

I understand the College is committed to improving and developing flexible training (Ramsay, 2005) and am pleased to report that such has been my experience. During my 2 years as a flexible trainee I have experienced some difficulties in attending all teaching sessions because some in-house sessions fell on days that I did not work. Most flexible trainees work six sessions (equivalent to 3 days) a week.

It would appear that flexible trainees are satisfied with current training schemes. Flexibly trained psychiatrists have been found to outperform their fulltime colleagues in terms of how quickly they gain College Membership (assessed by the number of examination attempts) (Mears et al, 2004). I am again pleased to report that this has been my experience.

It has been suggested that nationally $14 \%$ of all psychiatrists train flexibly
(Mears et al, 2004). In 2003 over $60 \%$ of all applicants to medical schools in the UK were female (British Medical Association, 2004). It seems reasonable to predict an increase in the number of women trainees in psychiatry (Ramsay, 2005). This could mean more trainees wanting to train flexibly.

I think it is very important that the College considers flexible training during the current revision so that the scheme will be compatible with part-time working.

BRITISH MEDICAL ASSOCIATION (2004) The Demography of Medical Schools: A Discussion Paper. London: BMA. http://www.bma.org.uk/ap.nsf/ Content/DemographyMedSchls/\$file/ demography.pdf

MEARS, A., ETCHEGOYEN, A., STORMONT, F., et al (2004) Female psychiatrists' career development after flexible training. Psychiatric Bulletin, 28, 201-203.

RAMSAY, R. (2005) Women in Psychiatry: ten years of a special interest group. Advances in Psychiatric Treatment, 11, 383-384.

Anu Ipe Senior House Officer in Psychiatry, Wonford House, Exeter EX2 7AF

\section{the college}

\section{Good Psychiatric Practice: Confidentiality and Information Sharing}

\section{Council Report CR133, March 2006, Royal College of Psychiatrists, $\mathrm{f10.00,}$} $48 \mathrm{pp}$

The central purpose of this report is to provide members with guidance on good practice in patient information privacy. This includes guidance on information sharing and on decisions about disclosure. It provides an in-depth development of the outline guidance given in Good Psychiatric Practice (CR125; Royal College of Psychiatrists, 2004)

In the interval since the first issue of these guidelines in 2000 there have been a number of changes in health service organisation, clinical practice and public expectations, as well as a general trend to augment the duty to disclose and to reduce professional privilege. Particular consideration has been given to the special issues surrounding the sensitivity of mental health information, the impact of changes in health service organisation, developments within practice (e.g. multidisciplinary and multi-agency working) and the impact of new technologies (e.g. electronic communication and computerised information systems).

The focus is on practical guidance relevant to a variety of situations and issues throughout the National Health Service and independent sector that confront psychiatrists and other members of multidisciplinary teams. Confidentiality is both an ethical and a legal issue and the approach adopted has been detailed in consideration of the ethical principles and legal framework that inform good practice.

The following topics are covered:

- Keeping patients and carers informed including information sharing to provide healthcare.

- Information sharing between users and carers.

- Multidisciplinary teams and interagency working.

- Disclosure, including where there is a legal requirement to disclose, and where decisions are matters of professional judgement

- Requests for case notes, providing reports.
- Media requests and video recording

- Secondary uses of patient information, including research.

\section{Services for Younger People with Alzheimer's Disease and Other Dementias}

Council Report CR135, March 2006, Royal College of Psychiatrists and Alzheimer's Society, f 10.00, $32 \mathrm{pp}$

Younger people with dementia and their carers frequently fall through the net of the health and social care services. During the 1990s an increasing number of these patients were referred to old age psychiatry services. In response to this new pattern, in 2000 the Royal College of Psychiatrists' Faculty of Old Age Psychiatry, in conjunction with the Alzheimer's Society, published a policy paper outlining the configuration of services for younger patients with dementia. The document was well received. In 2002 a review showed that a 